\title{
nature
}

10 March 2005 Volume 434 Issue no 7030

\section{Killers on the loose}

Across the developing world, seriously ill patients can't be sure whether they're purchasing life-saving medicines or worthless dummy pills. This scandal demands a stronger response from aid donors, governments and the drugs industry.

litistis

f you have ever been to southeast Asia, you'll probably have visited a street market laden with counterfeit goods. Maybe you even bought a knocked-off 'Rolex' watch or some pirated DVDs. It's all part of the Asian experience. Sure, it's illegal. But many visitors view the counterfeiters as Robin Hood-style outlaws, robbing rich Western companies to bolster the local cash economy.

But there is another side to Asia's culture of counterfeiting, which tourists don't usually get to see. The continent's pharmacies are awash with fake drugs that contain little or none of the labelled active ingredient. Produced mostly in China and India, these bogus products are also exported to Africa and the rest of the developing world. This trade is far from benign. It spawns chronic sickness, and leaves orphans and widows in its wake. It is run by ruthless individuals with scant regard for human life, and flourishes wherever they can induce corrupt officials to turn a blind eye.

Thankfully, awareness of the developing world's problems with fake pharmaceuticals is growing. Scientists and doctors who are trying to improve standards of healthcare in some of the world's poorest countries have helped to raise the alarm (see page 132). And in recent years, several programmes have been established to address the issue. The International Chamber of Commerce, for instance, launched a Counterfeit Pharmaceuticals Initiative in 2003 that acts as a clearinghouse for information about fake drugs.

Multinational drug companies have also begun to get involved. Several have come together to form the Pharmaceutical Security Institute, which gathers information on counterfeiting so that prosecutions can be pursued. Such actions have been driven by a growing
Internet trade in counterfeit drugs that is hitting 'big pharma' where it hurts - by targeting their rich, developed-world consumers.

But the industry, wary of sharing commercially sensitive information and fearing that publicity could undermine consumer confidence in its products, is still playing its cards close to its chest. And it is less than fully engaged with the problem in the developing world, where the human consequences of drug counterfeiting are most severe. Organizations fighting the menace of fake drugs say they'd like to do more but don't have the resources. Governments and drug companies should put those resources in place, and exert greater pressure on countries that harbour counterfeiters to bring them to justice.

One official working for a Western agency was told to lay off the issue, after invoking the ire of senior Cambodian officials by drawing attention to the country's fake drug problem and the corrupt environment in which it flourishes. Given that aid projects can only take place with the blessing of host governments, his superiors were presumably worried about jeopardizing all their efforts.

Such attitudes are misguided and unforgiveable. Many of the people behind the trade in fake drugs are former narcotics smugglers who have switched from a business where policing is stringent and penalties severe. These vicious, organized criminals are literally getting away with murder - a situation that should not be tolerated.

There are no easy answers. In the countries where the problems with fake drugs are most severe, it can be hard to tell who is part of the solution and who is part of the problem. But this is no excuse for inaction. As the philosopher Edmund Burke observed: "All that is necessary for the triumph of evil is that good men do nothing."

\section{Bad faith at Los Alamos}

\section{The breakdown of an old contract threatens to leave a great national laboratory gravely weakened.}

ए or an outsider, it's hard to imagine that conditions at Los Alamos National Laboratory in New Mexico could get much worse. When two disks containing classified data went missing last summer, federal investigators descended on the lab, operations were suspended for months, and scientists were berated as "buttheads" by Peter Nanos, the lab's director. Now, it turns out, those disks never existed (see Nature 433, 447; 2005).

Incredibly, Los Alamos could slide still further downhill. Its longstanding contract with the University of California, which manages the lab for the US Department of Energy, will be opened up to competition. At stake for lab employees is the academic clout that comes with the university's reputation, as well as a sterling pension plan for which many at the ageing lab are already eligible. Unless these benefits are protected, insiders fear that scientists will flee in droves.

Since Los Alamos was founded in 1943, its relationship with the university has been good for scientists. They enjoy the same privileges as university employees, including a lower tuition rate to the university's campuses and membership of the retirement programme.

But since 1999, university officials have spent countless hours responding to scandals, so some wonder whether it is worth the
$\$ 9$-million fee that the university receives. And the energy department has been embarrassed again and again by a never-ending string of security incidents - many of which may have been inflated by political animus towards the laboratory and its managers.

Looking for others interested in running the lab isn't a bad idea, but the exercise is creating too many uncertainties for scientists. If the lab were to go to another company, the university's pension plan and other benefits could be lost for ever. Along with the director's penchant for name-calling, it is no wonder that many older scientists are reportedly taking early retirement.

The best hope for fixing the contract might be Samuel Bodman, the incoming energy secretary. Bodman's credentials as former professor of chemical engineering at the Massachusetts Institute of Technology played well with the lab's rank-and-file during a meeting in February. And his previous job as president of Fidelity Investments has won him praise from congressional overseers. If he chooses to, he may be able to rebuild the lab's broken contract with the university, restore trust between the wounded parties, and ensure that researchers' benefits are protected. If he doesn't, Los Alamos could become just another ghost town in the New Mexico desert. 